\title{
Immunomodulatory Effects of Lycii Radicis Cortex Water Extract on Lipopolysaccharide-Activated RAW 264.7 Mouse Macrophages
}

\author{
Wansu Park
}

\author{
College of Korean Medicine, Gachon University, Seongnam 461-701, Republic of Korea
}

\begin{abstract}
The root bark of Lycium chinense Miller (Solanaceae), also known as Lycii radicis cortex, is one of famous plant-originated drugs in Korean medicine owing to its anti-tussive, anti-asthmatic, and antipyretic properties. In this study, the effect of Lycii radicis cortex water extract (LRC; $10-200 \mu \mathrm{g} / \mathrm{mL}$ ) on inflammatory mediators from lipopolysaccharide (LPS)-activated RAW 264.7 mouse macrophages was inspected. After $24 \mathrm{~h}$ incubation with LRC, cell viability, nitric oxide (NO), and various cytokines from RAW 264.7 were measured. LRC increased the cell viability of RAW 264.7 at concentrations of up to $200 \mu \mathrm{g} / \mathrm{mL}$. LRC significantly inhibited the production of NO, granulocyte colonystimulating factor (G-CSF), tumor necrosis factor- $\alpha$ (TNF- $\alpha$ ), platelet derived growth factor-BB (PDGF-BB), interleukin (IL)-2, and IL-10 in LPS-activated RAW $264.7(P<0.05)$. As well, LRC diminished the production of granulocytemacrophage colony-stimulating factor (GM-CSF) and lipopolysaccharide-induced CXC chemokine (LIX). The current results suggest that $L R C$ has immunomodulatory property to alleviate excessive immune reactions during the activation of macrophages by LPS.
\end{abstract}

Keywords: Lycii radicis, immunomodulatory, macrophage, cytokine, nitric oxide.

\section{INTRODUCTION}

The root bark of Lycium chinense Miller (family Solanaceae), also known as Lycii radicis cortex, is one of famous plant-originated drugs in Korean medicine owing to its anti-tussive, anti-asthmatic, and antipyretic properties [1]. In the Korean medical classic Donguibogam, which was nominated as Memory of the World by UNESCO in 2009, Lycii radicis cortex is explained as an important drug for treatment of diabetes mellitus, pneumonia, and systemic inflammation. It is also known to be remarkably effective in eliminating physical and mental fatigue [2]. Recently, it has been reported that Lycii radicis cortex has hypocholesterolemic, antioxidative, and hypoglycemic effects $[3,4]$.

Inflammation is necessary for immune reaction against various pathogenic invasions in human body. Maruotti et al. have reported that macrophages play a central role in the inflammatory response and serve as an essential interface between innate and adaptive immunity by modulating nitric oxide (NO), various cytokines like interleukin (IL) and tumor necrosis factor (TNF), prostaglandin E2 (PGE2), calcium, and hydrogen peroxide [5]. NO is a major component in the host innate immune reaction to various pathogens including bacteria, viruses, fungi, and other parasites [6]. Ilangumaran et al. have also reported that cytokines control the initiation, perpetuation, execution, and resolution of an immune response, which involves

*Address correspondence to this author at the College of Korean Medicine, Gachon University, Seongnam 461-701, Republic of Korea; Tel: +82-31-7508821; Fax: +82-31-750-8821; E-mail: hang198@naver.com temporally and spatially orchestrated interactions between different immune cells [7]. However, excessive and uncontrolled production of inflammatory mediators may lead to not only autoimmune disorders but also to serious systemic complications such as microcirculatory dysfunction, tissue damage, and septic shock with a resulting high mortality $[8,9]$. And Ramesh et al. have reported that the dysregulation of cytokines and chemokines (chemotactic cytokines) is a central feature in the development of neuroinflammation, neurodegeneration, and demyelination both in the central and peripheral nervous systems and in conditions of neuropathic pain [10].

In the present study, the effects of Lycii radicis cortex water extract (LRC) on the production of NO, IL2, IL-6, IL-10, TNF- $\alpha$, granulocyte colony-stimulating factor (G-CSF), inducible protein (IP)-10, leukemia inhibitory factor (LIF; IL-6 class cytokine), granulocyte macrophage colony-stimulating factor (GM-CSF), vascular endothelial growth factor (VEGF), interferon lipopolysaccharide-induced CXC chemokine (LIX), monocyte chemotactic protein (MCP)-1, macrophage inflammatory protein (MIP)-1 $\alpha$, MIP-1 $\beta, \quad$ MIP-2, RANTES/CCL5, macrophage-colony stimulating factor (M-CSF), and platelet derived growth factor (PDGF$\mathrm{BB}$ ), and in lipopolysaccharide (LPS)-activated RAW 264.7 mouse macrophages

\section{MATERIALS AND METHODS}

\subsection{Reagents}

Dulbecco's Modified Eagle's Medium (DMEM) and other tissue culture reagents were purchased from 
Gibco BRL (Grand Island, NY, USA). LPS and all other chemicals were purchased from Sigma-Aldrich (St. Louis, MO, USA) [11-15].

\subsection{Preparation of LRC}

Lycii radicis cortex was obtained from Omniherb (Daegu, Korea). A voucher specimen (No. 2013-07011) was deposited at Dept. of pathology, College of Korean Medicine, Gachon University. Because Lycii radicis cortex is traditionally extracted using water in Korean medicine, presently Lycii radicis cortex $(50 \mathrm{~g})$ was extracted with $2 \mathrm{~L}$ of boiling water for $2 \mathrm{~h}$, filtered, and then lyophilized (yield: $8.67 \%$ ). The powdered extract, LRC, was dissolved in saline and then filtered through a $0.22 \mu \mathrm{m}$ syringe filter [11-15].

\subsection{Cell Viability}

RAW 264.7 mouse macrophages were obtained from the Korea Cell Line Bank (Seoul, Korea). Cell viability was assessed using a modified MTT assay [11-15]. To eliminate the possibility of media amount as a confounder, media for cell culture were equally added in each well of 96 -well cell culture plates.

\subsection{Quantification of NO Production}

After $24 \mathrm{~h}$ incubation, NO concentration in the cultured medium was determined using a modified Griess reaction assay with a microplate reader (BioRad, Hercules, CA, USA) [11-15].

\subsection{Multiplex Bead-Based Cytokine Assay}

After $24 \mathrm{~h}$ incubation, cytokines in cell culture supernatants were measured using a Luminex assay based on XMAP technology. This assay was performed with Millipore multiplex cytokine assay kits (Millipore, Billerica, MA, USA) and Bio-Plex 200 suspension array system (Bio-Rad) as described previously [11-15]. Standard curves for each cytokine were generated using the kit-supplied reference cytokine samples. The following cytokine productions were analyzed: IL-1 $\beta$, IL-2, IL-6, IL-10, TNF- $\alpha$, G-CSF, GM-CSF, VEGF, IP10, LIF, LIX, MCP-1, MIP-1 $\alpha$, MIP-1 $\beta$, MIP-2, M-CSF, RANTES, and PDGF-BB.

\subsection{Statistical Analysis}

The statistical significance was examined by student's $t$-test using SPSS 11.0 software (SPSS, Chicago, IL, USA) [11-15]. In all cases, a $P$ value < 0.05 was considered significant.

\section{RESULTS}

\subsection{Effects of LRC on Cell Viability}

Cell viability of RAW 264.7 mouse macrophages in the presence of LRC is shown in Figures $\mathbf{1}$ and 2. Cytotoxicity of LRC (up to a concentration of 200 $\mu \mathrm{g} / \mathrm{mL}$ ) was not obvious after $24 \mathrm{~h}$ incubation. With this result, LRC concentrations of up to $200 \mu \mathrm{g} / \mathrm{mL}$ were chosen for subsequent experiments.

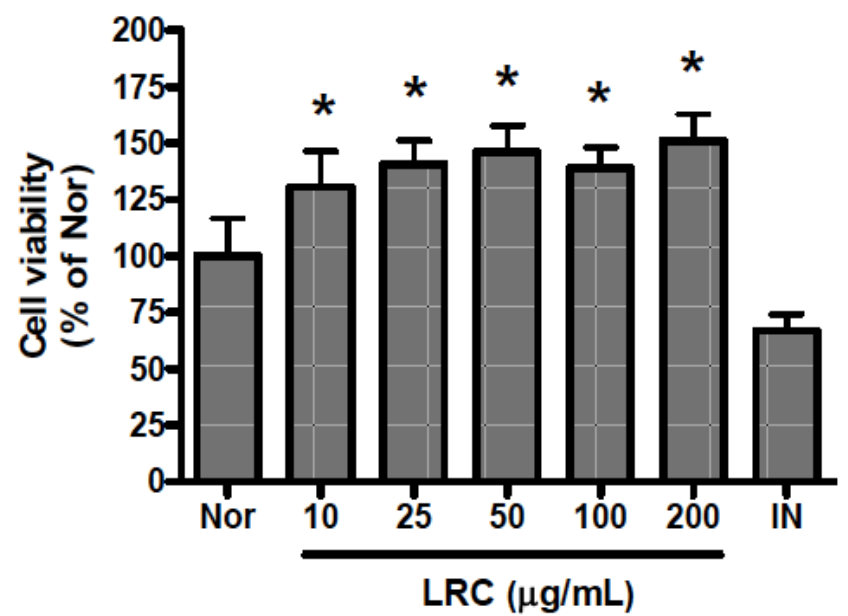

Figure 1: Effects of LCR on cell viability of RAW 264.7 mouse macrophages. After $24 \mathrm{~h}$ treatment, cell viability was evaluated by a modified MTT assay. Normal group (Nor) was treated with media only. Control group (Con) was treated with LPS $(1 \mu \mathrm{g} / \mathrm{mL})$ alone. IN denotes indomethacin $(0.5 \mu \mathrm{M})$. Values are the mean \pm SD of more than three independent experiments. ${ }^{*} P<0.05$ vs. Nor.

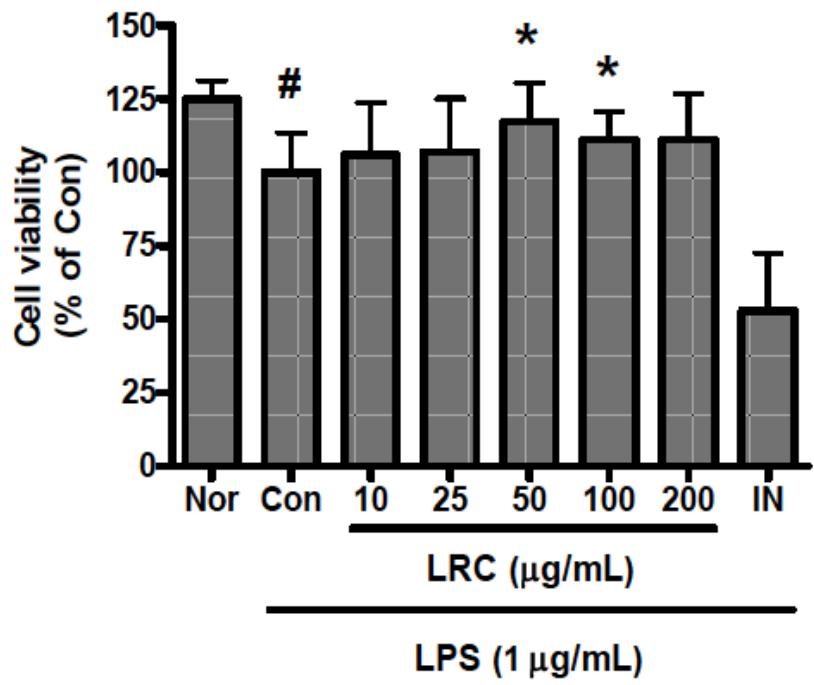

Figure 2: Effects of LCR on cell viability of LPS-activated RAW 264.7 mouse macrophages. After $24 \mathrm{~h}$ treatment, cell viability was evaluated by a modified MTT assay. Normal group (Nor) was treated with media only. Control group (Con) was treated with LPS $(1 \mu \mathrm{g} / \mathrm{mL})$ alone. IN denotes indomethacin $(0.5 \mu \mathrm{M})$. Values are the mean $\pm \mathrm{SD}$ of more than three independent experiments. ${ }^{*} P<0.05$ vs. Con. 


\subsection{Effects of LRC on LPS-Activated NO Production}

The effects of LRC on NO production in LPSstimulated RAW 264.7 mouse macrophages are shown in Figure 3. LRC significantly decreased NO production in LPS-activated RAW 264.7 mouse macrophages. In details, NO production of LPS-activated RAW 264.7 incubated with $10,25,50,100$, and $200 \mu \mathrm{g} / \mathrm{mL}$ LRC for $24 \mathrm{~h}$ were $73.18 \pm 10.19 \%, 73.4 \pm 8.44 \%, 71.95 \pm$ $5.17 \%, \quad 72.83 \pm 7.41 \%$, and $74.23 \pm 5.46 \%$, respectively $(P<0.05)$ of the control $(1 \mu \mathrm{g} / \mathrm{mL}$ of LPS alone) value.

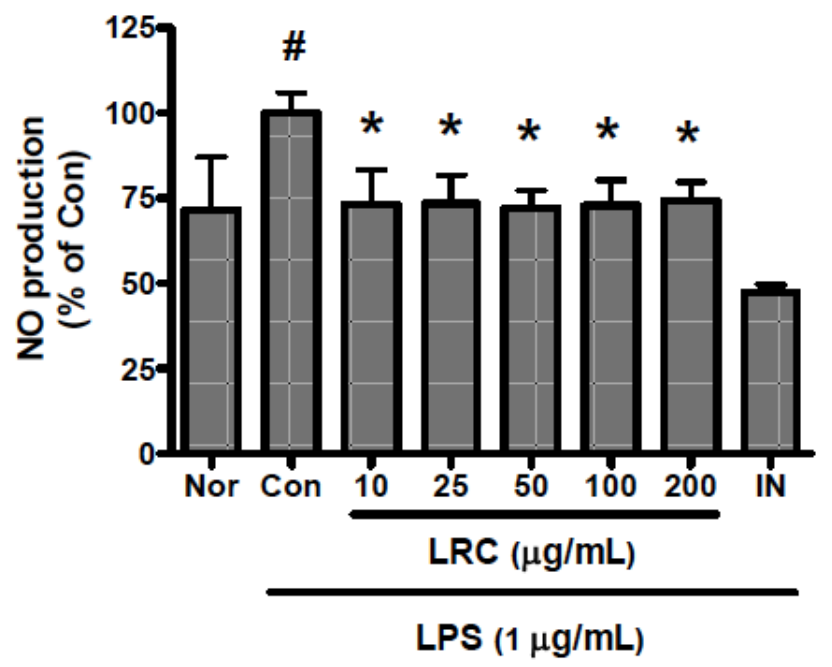

Figure 3: Effects of LRC on NO production in LPS-activated RAW 264.7 mouse macrophages. NO production was measured by the Griess reaction assay. Normal group (Nor) was treated with medium only. Control group (Con) was treated with LPS $(1 \mu \mathrm{g} / \mathrm{mL})$ alone. IN denotes indomethacin $(0.5 \mu \mathrm{M})$. Values are the mean \pm SD of more than three independent experiments. ${ }^{*} P<0.05$ vs. Con.

\subsection{Effects of LRC on LPS-Activated Cytokine Production}

The effects of LRC on cytokine production in LPSactivated RAW 264.7 are shown in Figure 4. Specifically, RAW 264.7 were treated with various concentrations of LRC and LPS $(1 \mu \mathrm{g} / \mathrm{mL})$ for $24 \mathrm{~h}$. LRC significantly decreased the production of TNF- $\alpha$, IL-10, PDGF-BB, IL-2, and G-CSF in LPS-activated RAW $264.7(P<0.05)$. As well, LRC diminished the production of GM-CSF and LIX in LPS-activated RAW 264.7. LRC did not show any significant effect on production of IL-1 $\beta$, IL-6, VEGF, IP-10, LIF, MCP-1, MIP-1 $\alpha$, MIP-1 $\beta$, MIP-2, RANTES, and M-CSF (data not shown).

\section{DISCUSSION}

It has been reported that Lycii Radicis Cortex contains approximately $2-5 \mathrm{mg} / \mathrm{g}$ of betaine which is a derivative of choline and this is known to have a pharmacological action $[2,16]$.

In the Korean medical classic Donguibogam, which was nominated as Memory of the World by UNESCO in 2009, Lycii radicis cortex is also explained as an ingredient in commonly-used herbal remedies for treatment of asthma, pneumonia, and diabetes mellitus.

Recently, Kim et al. have suggested that Lycium chinense, namely Lycii Radicis Cortex is a medicinal plant that is extensively consumed in Korea for the purpose of health improvement, and it is used in Korean medicine in its unpurified form as a tonic agent [2]. The experimental data have demonstrated that Lycii Radicis Cortex significantly decreases the immobility time in the forced swimming test (FST) and significantly increases both serotonin and norepinephrine levels in the hypothalamus of rats exposed to FST, indicating a possible antidepressantlike activity [2].

Cho et al. have reported that hypoglycemic effect of Lycii Radicis Cortex is confirmed in alloxan-induced diabetic mice, and a decrease in blood cholesterol and triglyceride level is also observed [3,4]. Additionally, Cho et al. have reported that Lycii Radicis Cortex inhibits skin damage caused by UV $[3,17]$ and hepatic damage caused by $\mathrm{CCl}_{4}[18]$.

In these days, herbal drug and plant medicine take interest of researchers more and more on account of their anti-inflammatory activity and the efficacy of the treatment for various inflammatory diseases [19]. But the effects of LRC on inflammatory mediators from LPS-activated macrophages had not been fully evaluated.

Cohen has reported that LPS, a kind of endotoxin, is a major component of the outer membrane of Gramnegative bacteria and one of the most potent microbial initiators of inflammation [20]. The current study investigated the immunomodulatory effects of LRC using LPS-activated RAW 264.7.

Centonze et al. have reported that a strong link between inflammation and neurodegeneration has recently emerged with evidence indicating that the two processes coexist from the very early stages of both classical neurodegenerative disorders and classical inflammatory diseases of the CNS [21]. Schultzberg et al. have reported that the activation of microglia and astrocytes with subsequent release of cytokines and 

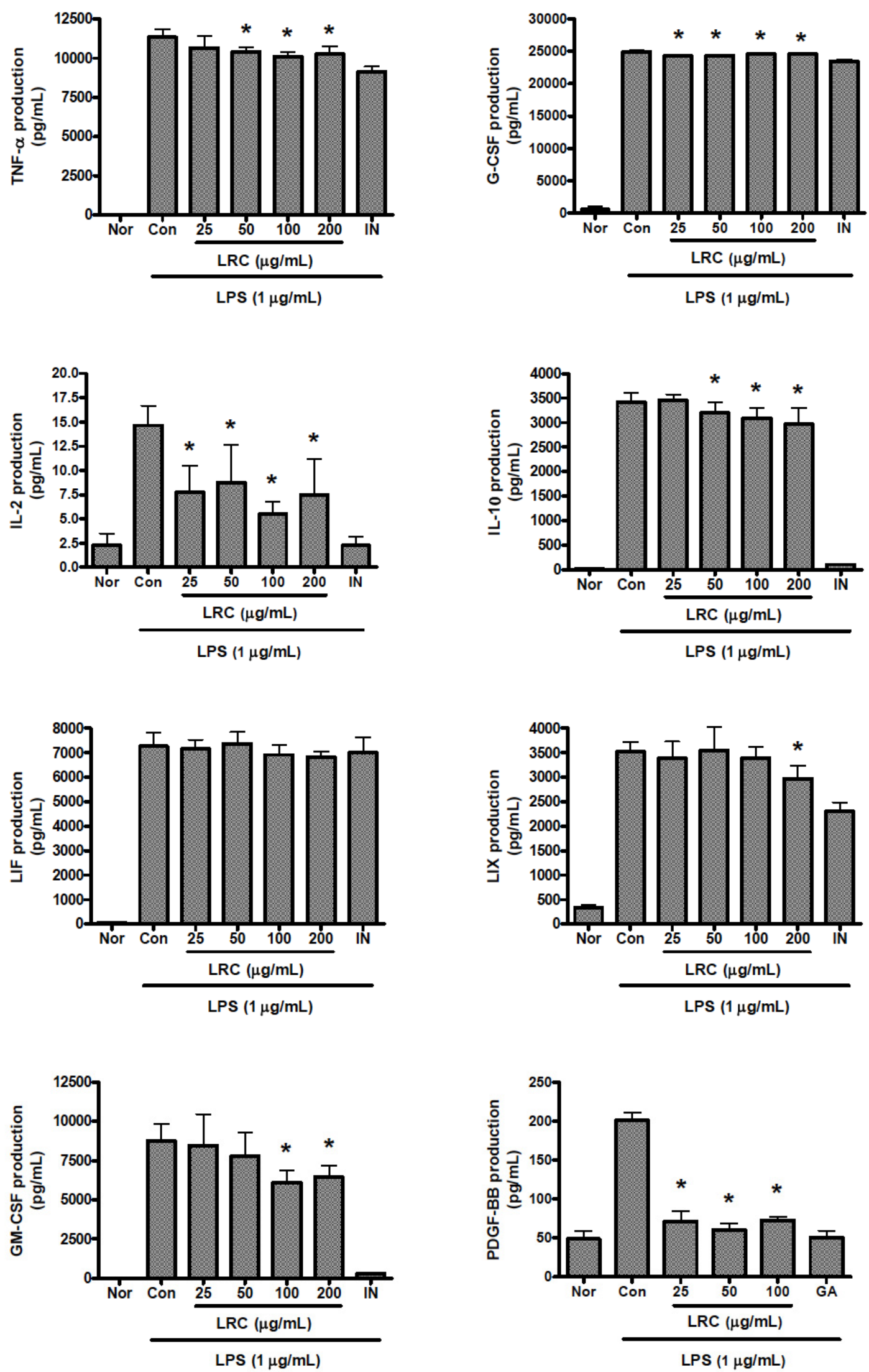

Figure 4: Effects of LRC on cytokine production in LPS-activated RAW 264.7 mouse macrophages. After $24 \mathrm{~h}$ incubation, cytokine concentration in the culture medium was measured by a Multiplex bead-based cytokine assay. Normal group (Nor) was treated with medium only. Control group (Con) was treated with LPS $(1 \mu \mathrm{g} / \mathrm{mL}$ ) alone. Gallic acid (100 $\mu M$; GA), and indomethacin $(0.5 \mu \mathrm{M} ; \mathrm{IN})$ were used as the positive controls. Values are the mean \pm SD of more than three independent experiments. ${ }^{*} P<0.05$ vs. Con. 
other inflammatory factors such as NO and cytokines are common features of both acute and chronic neurodegenerative disorders [22]. Centonze et al. have also reported that Alzheimer's disease, Parkinson's disease and amyotrophic lateral sclerosis are among the best examples of neurodegenerative disorders associated with intense inflammation, whereas multiple sclerosis and HIV-associated dementia are inflammatory disorders that lead to diffuse neuronal damage [21]. Block et al. have also reported that cytokines, bioactive peptides produced through complement activation, and other soluble factors mediate the toxic effects of microglia-produced inflammatory milieu on neurons [23, 24]. Allan et al. have also reported that pro-inflammatory cytokines such as TNF- $\alpha$ and IL-1 can cause blood-brain barrier breakdown, upregulate adhesion-molecule expression and induce vasogenic oedema, as well as trigger the release of toxic substances such as NO from the vascular endothelium [25]. In the current study, LRC inhibited LPS-activated production of NO and TNF- $\alpha$ in RAW 264.7. These results suggest the potential of LRC in coping with neurodegenerative disorders such as Alzheimer's disease and multiple sclerosis.

PDGF may be associated with neovascular agerelated macular degeneration [26]. Dace et al. have also reported that $\mathrm{IL}-10$, although traditionally considered an anti-inflammatory cytokine, has also been implicated in promoting abnormal angiogenesis in the eye and in the pathobiology of autoimmune diseases such as lupus and encephalomyelitis [27]. In this study, LRC significantly inhibited LPS-activated production of PDGF-BB and IL-10 in RAW 264.7. Thus, LRC might be one of medicinal plant material to treat various diseases concerned with angiogenesis.

The exaggerated allergic inflammatory disease with airway hyper-responsiveness like asthma can be accompanied by an increase in cytokines such as GCSF and IL-2, which are responsible for neutrophil and monocyte recruitment [28, 29]. Because LRC significantly inhibited LPS-activated production of GCSF and IL-2 in RAW 264.7, LRC may be useful in the modulation of various respiratory diseases concerned with airway inflammation.

As well, LRC diminished the production of GM-CSF and LIX in LPS-activated RAW 264.7.

\section{CONCLUSION}

According to the current experimental data, LRC increased the cell viability of RAW 264.7 at concentrations of up to $200 \mu \mathrm{g} / \mathrm{mL}$. And LRC significantly inhibited the production of NO, TNF- $\alpha$, PDGF-BB, IL-10, G-CSF, and IL-2 in LPS-activated RAW 264.7 mouse macrophages. As well, LRC diminished the production of GM-CSF and LIX. Detailed studies are needed to evaluate the pharmacological usefulness of LRC.

\section{CONFLICT OF INTEREST}

The authors have declared that there is no conflict of interest.

\section{REFERENCES}

[1] Xie LW, Atanasov AG, Guo DA, et al. Activity-guided isolation of NF-KB inhibitors and PPARy agonists from the root bark of Lycium chinense Miller. J Ethnopharmacol 2014; 152(3): 470-7.

http://dx.doi.org/10.1016/j.jep.2014.01.029

[2] Kim SJ, Lee MS, Kim JH, Lee TH, Shim I. AntidepressantLike Effects of Lycii Radicis Cortex and Betaine in the Forced Swimming Test in Rats. Biomol Ther 2013; 21: 79-83. http://dx.doi.org/10.4062/biomolther.2012.072

[3] Cho SH, Park EJ, Kim EO, Choi SW. Study on the hypochlolesterolemic and antioxidative effects of tyramine derivatives from the root bark of Lycium chenese Miller. Nutr Res Pract 2011; 5: 412-20.

http://dx.doi.org/10.4162/nrp.2011.5.5.412

[4] Gao D, Li Q, Liu Z, et al. Hypoglycemic effects and mechanisms of action of Cortex Lycii Radicis on alloxaninduced diabetic mice. Yakugaku Zasshi 2007; 127: 1715-21. http://dx.doi.org/10.1248/yakushi.127.1715

[5] Maruotti N, Cantatore FP, Crivellato E, Vacca A, Ribatti D. Macrophages in rheumatoid arthritis. Histol Histopathol 2007; 22: $581-6$.

[6] Bogdan $C$, Röllinghoff $M$, Diefenbach $A$. The role of nitric oxide in innate immunity. Immunol Rev 2000; 173: 17-26. http://dx.doi.org/10.1034/j.1600-065X.2000.917307.x

[7] Ilangumaran S, Ramanathan S, Rottapel R. Regulation of the immune system by SOCS family adaptor proteins. Semin Immunol 2004; 16: 351-65. http://dx.doi.org/10.1016/j.smim.2004.08.015

[8] O'Shea JJ, Ma A, Lipsky P. Cytokines and autoimmunity. Nature Reviews Immunology 2002; 2: 37-45. http://dx.doi.org/10.1038/nri702

[9] Ulevitch RJ, Tobias PS. Receptor-dependent mechanisms of cell stimulation by bacterial endotoxin. Annu Rev Immunol 1995; 13: 437-57.

http://dx.doi.org/10.1146/annurev.iy.13.040195.002253

[10] Ramesh G, MacLean AG, Philipp MT. Cytokines and chemokines at the crossroads of neuroinflammation, neurodegeneration, and neuropathic pain. Mediators Inflamm 2013; 2013: 480739.

http://dx.doi.org/10.1155/2013/480739

[11] Yoon SB, Lee YJ, Park SK, et al. Anti-inflammatory effects of Scutellaria baicalensis water extract on LPS-activated RAW264.7 macrophages. J Ethnopharmacol 2009; 125: 28690 http://dx.doi.org/10.1016/i.jep.2009.06.027

[12] Yuk SS, Lim EM, Lee JY, Lee YJ, Kim YS, Lee TH, et al. Antiinflammatory effects of Epimedium brevicornum water $\begin{array}{lll}\text { extract on lipopolysaccharide-activated RAW264.7 } & \end{array}$ macrophages. Phytother Res 2010; 24: 1781-7. http://dx.doi.org/10.1002/ptr.3161 
[13] Lee JY, Park W. Anti-Inflammatory Effect of Myristicin on RAW 264.7 Macrophages Stimulated with PolyinosinicPolycytidylic Acid. Molecules 2011; 16: 7132-42. http://dx.doi.org/10.3390/molecules16087132

[14] Lee JY, Park W, Yi DK. Immunostimulatory effects of gold nanorod and silica-coated gold nanorod on RAW 264.7 mouse macrophages. Toxicol Lett 2012; 209: 51-7. http://dx.doi.org/10.1016/j.toxlet.2011.11.024

[15] Kim HK, Lee JY, Han HS, et al. Immunomodulatory Effects of Liriope Platyphylla Water Extract on LipopolysaccharideActivated Mouse Macrophage. Nutrients 2012; 4: 1887-97. http://dx.doi.org/10.3390/nu4121887

[16] Schwab U, Torronen A, Meririnne E, et al. Orally administered betaine has an acute and dose-dependent effect on serum betaine and plasma homocysteine concentrations in healthy humans. J Nutr 2006; 136: 34-8.

[17] Ahn BY, Gwak JS, Ryu SH, et al. Protective effect of water extract of Lycii Cordex Radicis on lipid peroxidation of rat skin exposed to ultraviolet $B$ radiation. Agric Chem Biotechnol 2002; 45: 218-22.

[18] Cho YJ, Kim SH. Protective effect of EA fraction of Lycii Cortex Radix on the hepatic damage in mice induced by CCl4. Korean J Orient Med Pathol 1997; 11: 63-71.

[19] Hsieh SC, Fang SH, Rao YK, Tzeng YM. Inhibition of proinflammatory mediators and tumor cell proliferation by Anisomeles indica extracts. J Ethnopharmacol 2008; 118: 6570.

http://dx.doi.org/10.1016/j.jep.2008.03.003

[20] Cohen J. The immunopathogenesis of sepsis. Nature 2002; 420: 885-91. http://dx.doi.org/10.1038/nature01326

[21] Centonze D, Finazzi-Agro A, Bernardi G, Maccarrone M. The endocannabinoid system in targeting inflammatory neurodegenerative diseases. Trends Pharmacol Sci 2007; 28: $180-7$.

http://dx.doi.org/10.1016/j.tips.2007.02.004
[22] Schultzberg M, Lindberg C, Aronsson AF, Hjorth E, Spulber $\mathrm{SD}$, Oprica M. Inflammation in the nervous system Physiological and pathophysiological aspects. Physiol Behav 2007; 92: 121-8.

http://dx.doi.org/10.1016/j.physbeh.2007.05.050

[23] Block ML, Hong JS. Microglia and inflammation-mediated neurodegeneration: multiple triggers with a common mechanism. Prog Neurobiol 2005; 76: 77-98. http://dx.doi.org/10.1016/j.pneurobio.2005.06.004

[24] Bonifati DM, Kishore $U$. Role of complement in neurodegeneration and neuroinflammation. Mol Immunol 2007; 44: 999-1010. http://dx.doi.org/10.1016/j.molimm.2006.03.007

[25] Allan SM, Rothwell NJ. Inflammation in central nervous system injury. Phil Trans R Soc Lond B 2003; 358: 1669-77. http://dx.doi.org/10.1098/rstb.2003.1358

[26] Funk M, Karl D, Georgopoulos M, et al. Neovascular agerelated macular degeneration: intraocular cytokines and growth factors and the influence of therapy with ranibizumab. Ophthalmoloy 2009; 116: 2393-9. http://dx.doi.org/10.1016/j.ophtha.2009.05.039

[27] Dace DS, Khan AA, Stark JL, Kelly J, Cross AH, Apte RS Interleukin-10 overexpression promotes Fas-liganddependent chronic macrophage-mediated demyelinating polyneuropathy. Plos One 2009; 4: e7121. http://dx.doi.org/10.1371/journal.pone.0007121

[28] Sheller JR, Polosukhin VV, Mitchell D, Cheng DS, Peebles RS, Blackwell TS. Nuclear factor kappa B induction in airway epithelium increases lung inflammation in allergenchallenged mice. Exp Lung Res 2009; 35: 883-95. http://dx.doi.org/10.3109/01902140903019710

[29] Akbar AN, Borthwick NJ, Wickremasinghe RG, et al. Interleukin-2 receptor common gamma-chain signalling cytokines regulate activated $T$ cell apoptosis in response to growth factor withdrawal: selective induction of anti-apoptotic (bcl-2, bcl-x(L) but not pro-apoptotic (bax, bcl-x(S)) gene expression. Eur J Immunol 1996; 26: 294-9. http://dx.doi.org/10.1002/eji.1830260204

\section{DOI: http://dx.doi.org/10.6000/1927-5951.2014.04.03.6}

(C) 2014 Wansu Park; Licensee Lifescience Global.

This is an open access article licensed under the terms of the Creative Commons Attribution Non-Commercial License (http://creativecommons.org/licenses/by-nc/3.0/) which permits unrestricted, non-commercial use, distribution and reproduction in any medium, provided the work is properly cited. 